\title{
Long-term effect of YAG laser iridotomy on corneal endothelium in primary angle closure suspects: a 72-month randomised controlled study
}

\author{
Chimei Liao, ${ }^{1}$ Jian Zhang, ${ }^{1}$ Yuzhen Jiang, ${ }^{2}$ Shengsong Huang, ${ }^{1}$ Tin Aung, ${ }^{3}$ \\ Paul J Foster, ${ }^{4}$ David Friedman, ${ }^{5}$ Mingguang He (1) 1,6
}

${ }^{1}$ State Key Laboratory of Ophthalmology, Zhongshan Ophthalmic Center, Sun Yat-sen University, Guangzhou, China ${ }^{2}$ Moorfield Eye Hospital NHS Foundation Trust, London, UK ${ }^{3}$ Singapore Eye Research Institute and Singapore National Eye Center, Singapore ${ }^{4} \mathrm{NIHR}$ Biomedical Research Center at Moorfields Eye Hospital and UCL Institute of Ophthalmology, London, UK ${ }^{5}$ Massachusetts Eye and Ear, Harvard Medical School Department of Ophthalmology, Boston, Massachusetts, USA ${ }^{6}$ Center for Eye Research Australia, University of Melbourne, Royal Victorian Eye and Ear Hospital, Melbourne, Victoria, Australia

\section{Correspondence to}

Dr Mingguang He, State Key Laboratory of Ophthalmology, Zhongshan Ophthalmic Center, Sun Yat-sen University, Guangzhou 510060, China: mingguanghe@gmail.com

PJF, DF and $\mathrm{MH}$ are joint senior authors.

Received 6 January 2020 Revised 30 March 2020 Accepted 27 April 2020 Published Online First 19 May 2020

\section{ABSTRACT \\ Purposes To evaluate the effect of YAG laser peripheral} iridotomy (LPI) on corneal endothelial cell density (ECD) and morphology in primary angle closure suspects (PACS) over 72 months.

Methods The Zhongshan Angle Closure Prevention Trial is a single-centre randomised controlled trial. Subjects with bilateral PACS received YAG LPI prophylactic treatment in one eye randomly, while the fellow eye served as control. Central corneal ECD and morphology were assessed using non-contact specular microscopy (SP-2000P, Topcon) at baseline, 6, 18, 36, 54 and 72 months postoperatively. Mixed model analysis was conducted to compare the difference between treated and fellow eyes.

Results A total of 875 participants were included, with a mean age of $59.3 \pm 5.0$ years and $83.5 \%$ female. The ECD declined significantly $(p<0.001)$ over time in both treated and fellow eyes, but the treated eyes showed more progressive cell loss with increasing time $(p<0.001)$. The difference in ECD loss between LPI-treated and fellow eyes was not significant at each follow-up until 72 months (4.9\% in LPI eyes vs $4.2 \%$ in non-LPI eyes, $p=0.003$ ). Mean cell areas increased significantly over time in both treated and fellow eyes $(p<0.001)$, but no longitudinal change was observed for hexagonality. In LPI-treated eyes, no significant correlation was found between age, gender, ocular biometrics, intraocular pressure and laser settings with endothelium change, except for time effect $(p<0.01)$. Conclusion ECD decreases over time primarily due to ageing effect. YAG LPI does not appear to cause clinically significant corneal endothelial damage over 72 months after treatment.

Trial registration number ISRCTN45213099.

\section{INTRODUCTION}

Primary angle closure glaucoma (PACG) accounts for nearly a half of global blindness caused by glaucoma. ${ }^{1}$ Laser peripheral iridotomy (LPI) is the conventional first-line treatment for individuals with primary angle closure. ${ }^{2}$ Previous evidence suggests that LPI can reduce elevated intraocular pressure (IOP) in primary angle closure (PAC) and reduce the risk of primary angle closure suspects (PACS) developing more PAC or acute attacks. ${ }^{34}$ While LPI is generally felt to be safe, there have been reports of corneal complications including oedema and decompensation after argon laser iridotomies. $^{56}$
Compared with the photocoagulative thermal mechanism of an argon laser, neodymium-doped yttrium aluminium garnet (Nd:YAG) laser causes photodisruption of target tissues with a high-power density, fewer spots of shorter duration and less energy for iris penetration. Although sequential argon-YAG may be preferred especially in dark iris and in the absence of iris crypts, ${ }^{7}$ the use of combined laser may be less cost-effective and unaffordable for some eye care organisations. To our knowledge, the short-term safety of Nd:YAG LPI has been established, but long-term evaluation is limited. ${ }^{8}$ A previous study observed no significant change of endothelial cell count in 126 eyes underwent Nd:YAG LPI after 1 year. ${ }^{9}$ Ramani et al ${ }^{10}$ also noted no significant change in central corneal thickness in 82 eyes 2 years after Nd:YAG LPI. However, corneal decompensation after LPI may be late-onset, evidenced by some studies reporting that bullous keratopathy or corneal oedema occurred years after the LPI procedure. ${ }^{511}$ Moreover, it is well known that cell count and corneal cell morphology is relevant to corneal endothelial function and decompensation. Limited studies have reported the effect of $\mathrm{Nd}$ :YAG laser on endothelial hexagonality using retrospective design ${ }^{12}$ or without comparison. ${ }^{13}$ The long-term effect needs to be evaluated with further study.

The Zhongshan Angle Closure Prevention (ZAP) Trial is a single-centre, randomised interventional controlled trial with the aims to evaluate the efficacy and safety of LPI for preventing PAC events in PACS subjects. The aim of the current analysis was to evaluate the influence of Nd:YAG LPI on corneal endothelial cell density (ECD) and morphology in PACS patients over 72 months.

\section{METHODS}

Study participants were recruited from a randomised controlled clinical trial, the ZAP trial. The International Standard Randomised Controlled Trial Number was issued on 6 May 2008. Written informed consent was obtained from all participants before enrolling.

Details of the sampling and recruitment methodology for this trial have been described previously. ${ }^{14}$ In brief, participants aged 50-70 years from an urban district in Guangzhou diagnosed as bilateral PACS were enrolled. PACS was defined as the presence of 6 or more clock hours of angle circumference in which the posterior trabecular meshwork 
was not visible under static gonioscopy, with IOP $\leq 21 \mathrm{~mm}$ $\mathrm{Hg}$, absence of peripheral anterior synechiae or glaucomatous optic neuropathy and no evidence of anterior segment ischaemia from a previous acute IOP increase. Subjects with severe health problems, history of intraocular surgery or penetrating eye injury, media opacity preventing LPI, best-corrected visual acuity worse than $20 / 40$ or IOP increase $>15 \mathrm{~mm} \mathrm{Hg}$ after dilation or after a $15 \mathrm{~min}$ dark room prone provocative testing were excluded. All eligible participants underwent prophylactic LPI in one randomly selected eye, while the fellow eye served as a control. The randomisation was carried out with a pregenerated list of random numbers. Each eligible participant was assigned a number according to his/her sequence of entering the study. Randomisation numbers and their corresponding eye assignment were generated at the data monitoring centre at Wilmer Eye Institute and sent to the clinical data collection centre at Zhongshan Ophthalmic Centre in sealed envelopes.

Comprehensive eye examinations were conducted at baseline and each follow-up on all eligible participants. ${ }^{14}$ The IOP was measured using Goldmann applanation tonometry (HaagStreit AG, Koeniz, Switzerland). The median of three readings for each eye was considered. Ocular biometric measures such as axial length (AL), central anterior chamber depth (ACD) and lens thickness (LT) were acquired using ultrasound A-scan (CineScan A/B, Quantel Medical, Bozeman, Montana, USA). Static and dynamic gonioscopy was done by a single observer after topical anaesthetic. Static gonioscopy was performed with a one mirror gonioscopic lens (Single Mirror Gonioscope, Ocular Instruments, Bellevue, Washington, USA) with a $1 \mathrm{~mm}$ narrow beam. If trabecular meshwork was invisible during the static gonioscopy, a dynamic examination with a four mirror gonioscopic lens (Sussman Four Mirror Gonioscope, Ocular Instruments) was performed to determine the existence of peripheral anterior synechiae.

All subjects underwent central corneal endothelium assessment bilaterally using a non-contact, semi-automated specular microscope (SP-2000P, Topcon, Tokyo, Japan). This instrument can capture a digital image of the corneal endothelium and automatically calculate the number of cells per $\mathrm{mm}^{2}$ (ECD), average cell size and percentage of hexagonal cells in the area analysed (hexagonality, \%) with the combined Endothelial Cell Analysis Module in the IMAGEnet 2000 software package. ECD was recorded to track the cell loss. The average cell size was used to measure the extent of variation in cell area (polymegathism) while the hexagonality was used as an index of variation in cell shape (pleomorphism). The instrument was calibrated before performing measurements and image analyses were performed after calibration of the magnification. ${ }^{15}$ The central region of corneal endothelial images were captured by a trained nurse using the autofocus mode with low flash intensity. Only images with clear cell margins in most areas and with a quality index 2.0 or greater were saved. The quality of images was monitored at the time of acquisition by the operator and reviewed monthly by quality control supervisors. During the image analysis, the operator was encouraged to choose the area where cells displayed sharply defined margins. After the region of interest was defined manually, the software gave measurements automatically. Then the operator retraced the ill-traced cell borders, added missing cell borders and deleted falsely recognised cell borders with the analytic tool (figure 1). For each patient, analysis was performed with the most representative image for one time. On average, a number of $88.7 \pm 15.7$ cells were analysed in a single image. Patients with ECD $<1000$ cells $/ \mathrm{mm}^{2}$ were excluded from the study for safety reasons.
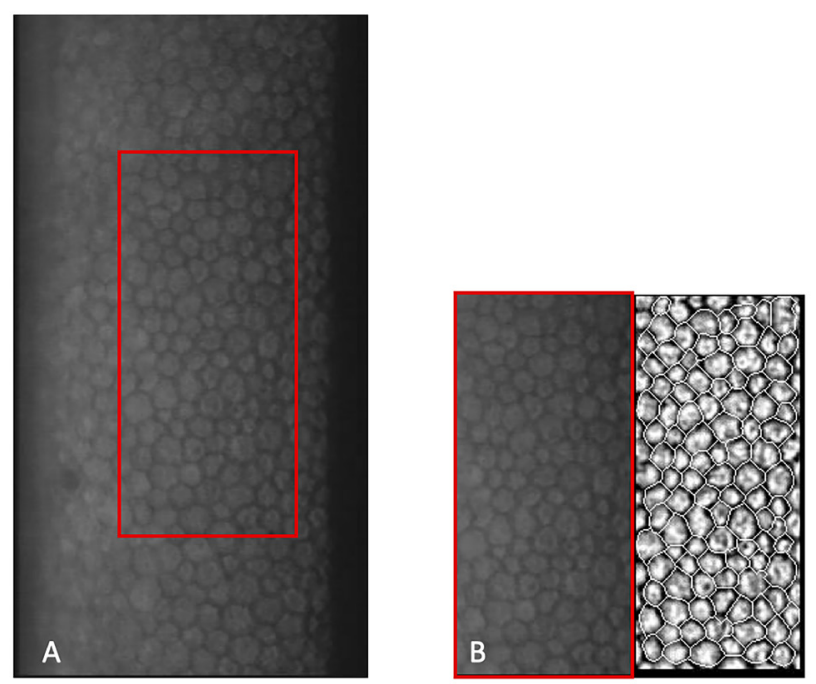

Figure 1 Endothelial image generated by the SP-2000P and analysis in the IMAGEnet system. Picture $A$ is the original image, within which the red box indicates the region of interest. Picture $B$ is the analysis of endothelium in the region of interest after retraced operation. A total of 102 cells with an average size of $334.2 \mu \mathrm{m}^{2}$ were analysed in this image. The estimation of cell density was $2992.3 / \mathrm{mm}^{2}$ and hexagonality was $56 \%$.

Fifteen minutes after the administration of $2 \%$ pilocarpine and $0.15 \%$ brimonidine eye drops, LPI was performed using YAG laser (Visulas YAG III, Carl Zeiss Meditec, Dublin, California, USA) with the use of an Abraham lens (Ocular Instruments). The laser irradiated the iris with an initial setting of $1.5 \mathrm{~mJ}$ increasing as needed to create a patent iridotomy of at least $200 \mu \mathrm{m}$ in diameter. The LPI was placed in a crypt or other area where the iris appeared thinnest and was positioned beneath the superior lid. The IOP was checked 1 hour postoperatively. Individuals who had an increase in IOP $>8 \mathrm{~mm} \mathrm{Hg}$ was given a drop of brimonidine and a tablet of acetazolamide $250 \mathrm{mg}$ (if without contraindication). The pressure was re-checked 1 hour later. If it had not further risen over the second hour, then the patient would be discharged and examined the following morning. Otherwise, the patient would be referred to a glaucomatologist for further management. All participants were prescribed dexamethasone drops applied hourly for 24 hours (unless during sleeping) after surgery and then four times daily for 1 week.

Patients were required to return for follow-up visits at 2 weeks, 6 months, 18 months, 36 months, 54 months and 72 months. The observation for endothelial changes ended when the treated and untreated eyes reached one of the following end points: (1) IOP above $24 \mathrm{mmHg}$ on two separate occasions; (2) development of peripheral anterior synechiae $\geq 1$ clock hour in any quadrants or (3) development of acute attack.

\section{Statistical analysis}

Differences in baseline characteristics between the LPI and nonLPI groups were assessed with standard parametric tests ( $t$-test) if data were normally distributed and non-parametric tests (Mann-Whitney U test) if the data were not normally distributed. Changes in endothelial cell parameters were compared between the LPI and non-LPI groups using mixed-effects models. Time after operation was set as the time variable and calculated per month. Unstructured covariance structure was selected after comparing other covariate structures, such as the variance 
Table 1 Baseline characteristics of treated and fellow eyes $(n=875)$

\begin{tabular}{llcl}
\hline Characteristics & LPI & Non-LPI & P value \\
\hline Age (years) & $59.3 \pm 5.0$ & & - \\
\hline Female $(\%)$ & $731(83.5)$ & & - \\
\hline Endothelial cell density $\left(\right.$ per $\left.\mathrm{mm}^{2}\right)$ & $2571.4 \pm 300.3$ & $2571.9 \pm 304.9$ & 0.94 \\
Mean cell area $\left(\mu \mathrm{m}^{2}\right)$ & $394.9 \pm 53.9$ & $395.0 \pm 54.0$ & 0.96 \\
Hexagonality $(\%)$ & $56.5 \pm 9.4$ & $56.9 \pm 9.4$ & 0.38 \\
\hline
\end{tabular}

LPI, laser peripheral iridotomy

component, compound symmetry, first-order autoregressive and Toeplitz, based on the smallest Akaike Information Criterion and Bayesian Information Criterion values. All of the model covariates were adjusted for age at baseline and gender. Group assignment, follow-up time and group $\times$ time interactions were included as fixed effects. Mean changes and 95\% CIs derived from the mixed models were calculated. P values $<0.05$ were considered to be statistically significant. Statistical analyses were performed using SAS V.9.2 (SAS Institute).

\section{RESULTS}

Of the 889 eligible participants enrolled at baseline, 875 participants with complete data were included in the analysis. The mean age was $59.3 \pm 5.0$ years and $83.5 \%$ were women $(n=875)$. Twelve participants had repeat LPI to complete the iridotomy and 15 participants had LPI in the control eye before the last follow-up examination. The baseline characteristics of treated eyes and controls eyes are displayed in table 1 . No significant difference in specular biomicroscopy parameters was observed between treated and fellow eyes at baseline (all with $\mathrm{p}>0.05$ ).

ECD decline over time in eyes with or without LPI treatment (table 2). The difference in ECD between LPI-treated and fellow eyes was not significant at each follow-up until 72 months after operation. The mean per cent reduction of ECD from the preoperative to the 72-month postoperative was 4.93\% (95\% CI: $-5.3 \%$ to $-4.57 \%)$ in LPI-treated eyes and $4.2 \%$ (95\% CI: $-4.57 \%$ to $-3.83 \%)$ in untreated eyes, respectively $(\mathrm{p}=0.003)$.
Table 3 Mixed model estimates of risk factors for longitudinal crude changes of corneal endothelial cells parameters over 72 months

\begin{tabular}{lcc}
\hline Multivariate models & Estimate $(95 \% \mathrm{Cl})$ & P value \\
\hline Endothelial cell density (per $\mathrm{mm}^{2}$ ) & & \\
\hline Age at baseline (years) & $-1.45(-2.32$ to -0.58$)$ & 0.001 \\
Gender (male as reference) & $-5.27(-16.77$ to 6.24$)$ & 0.37 \\
Group (non-LPl eye as reference) & $6.07(-2.46$ to 14.61$)$ & 0.16 \\
Time (month) & $-1.60(-1.72$ to -1.48$)$ & $<0.001$ \\
Timexgroup & $-0.32(-0.49$ to -0.15$)$ & 0.0002 \\
Mean cell area ( $\left.\mu \mathrm{m}^{2}\right)$ & & \\
Age at baseline (years) & $0.18(0.05$ to 0.31$)$ & 0.007 \\
Gender (male as reference) & $1.21(-0.51$ to 2.93$)$ & 0.17 \\
Group (non-LPl eye as reference) & $-0.68(-2.01$ to 0.65$)$ & 0.32 \\
Time (month) & $0.23(0.22$ to 0.25$)$ & $<0.001$ \\
Timexgroup & $0.03(0.01$ to 0.06$)$ & 0.008 \\
Hexagonality (\%) & & \\
Age at baseline (years) & $0(-0.07$ to 0.07$)$ & 0.98 \\
Gender (male as reference) & $0.62(-0.30$ to 1.54$)$ & 0.18 \\
Group (non-LPl eye as reference) & $-0.07(-0.77$ to 0.63$)$ & 0.85 \\
Time (month) & $0(0$ to 0.01$)$ & 0.28 \\
Timexgroup & $0.01(-0.01$ to 0.02$)$ & 0.28 \\
\hline
\end{tabular}

Timexgroup=interaction between time and group. Bold indicates statistical significance.

LPI, laser peripheral iridotomy.

Additionally, the mean cell area and the hexagonality of cells increased in both eyes, but the differences were not significant between groups over time, except for the mean cell area measurement at 54-month follow-up ( $\mathrm{p}=0.03$ ).

Mixed model analysis was conducted to investigate risk factors for longitudinal changes in corneal endothelial cells parameters (table 3). Baseline age was significantly negatively associated with ECD level, as older patients had greater endothelial cell loss at each timepoint $(p=0.001)$. The cell density declined significantly $(p<0.001)$ over time in both treated and fellow eyes, but

\begin{tabular}{|c|c|c|c|c|c|c|c|}
\hline \multirow[b]{2}{*}{ Month } & \multicolumn{3}{|c|}{ Absolute change (mean $(95 \% \mathrm{CI}))$} & \multicolumn{3}{|c|}{ Percentage change $(\%(95 \% \mathrm{CI}))$} & \multirow[b]{2}{*}{$P$ value } \\
\hline & LPI eye & Non-LPI eye & Treatment effect & LPI eye & Non-LPI eye & Treatment effect & \\
\hline \multicolumn{8}{|c|}{ Endothelial cell density (per $\mathrm{mm}^{2}$ ) } \\
\hline 6 & $-11.8(-20.2$ to -3.3$)$ & $-20.3(-28.8$ to -11.9$)$ & $8.6(-2.9$ to 20.1$)$ & $-0.39(-0.72$ to -0.06$)$ & $-0.65(-0.98$ to -0.32$)$ & $0.26(-0.19$ to 0.71$)$ & 0.14 \\
\hline 18 & $-25.4(-33.8$ to -17$)$ & $-26.4(-34.8$ to -17.9$)$ & $1.0(-10.5$ to 12.4$)$ & $-0.97(-1.3$ to -0.63$)$ & $-0.93(-1.26$ to -0.6$)$ & $-0.03(-0.48$ to 0.41$)$ & 0.87 \\
\hline 36 & $-65.5(-74.2$ to -56.9$)$ & $-62.4(-71.1$ to -53.7$)$ & $-3.1(-14.9$ to 8.7$)$ & $-2.5(-2.84$ to -2.16$)$ & $-2.38(-2.72$ to -2.04$)$ & $-0.12(-0.58$ to 0.34$)$ & 0.61 \\
\hline 54 & $-117.9(-126.9$ to -108.9$)$ & $-106.3(-115.3$ to -97.2$)$ & $-11.6(-23.9$ to 0.7$)$ & $-4.56(-4.92$ to -4.21$)$ & $-4.08(-4.44$ to -3.73$)$ & $-0.48(-0.96$ to 0$)$ & 0.06 \\
\hline 72 & $-127.8(-137$ to -118.6$)$ & $-108.4(-117.8$ to -99$)$ & $-19.4(-32.1$ to -6.7$)$ & $-4.93(-5.3$ to -4.57$)$ & $-4.2(-4.57$ to -3.83$)$ & $-0.74(-1.23$ to -0.24$)$ & 0.003 \\
\hline \multicolumn{8}{|c|}{ Mean cell area $\left(\mu \mathrm{m}^{2}\right)$} \\
\hline 6 & $1.1(-0.2$ to 2.3$)$ & $1.8(0.6$ to 3.1$)$ & $-0.8(-2.5$ to 0.9$)$ & $0.35(0.05$ to 0.66$)$ & $0.6(0.29$ to 0.9$)$ & $-0.24(-0.67$ to 0.18$)$ & 0.38 \\
\hline 18 & 3.5 (2.2 to 4.7$)$ & $3.7(2.4$ to 4.9$)$ & $-0.2(-1.9$ to 1.5$)$ & 0.94 (0.63 to 1.25$)$ & 1.04 (0.73 to 1.35$)$ & $-0.1(-0.53$ to 0.33$)$ & 0.81 \\
\hline 36 & 9.0 (7.7 to 10.3$)$ & 9.3 (8 to 10.5 ) & $-0.3(-2$ to 1.5$)$ & 2.4 (2.08 to 2.72 ) & 2.43 (2.12 to 2.75$)$ & $-0.03(-0.47$ to 0.4$)$ & 0.75 \\
\hline 54 & 17.3 (16 to 18.6 ) & 15.2 (13.9 to 16.6$)$ & $2.1(0.2$ to 3.9$)$ & 4.48 (4.15 to 4.8$)$ & 3.99 (3.66 to 4.33 ) & $0.48(0.02$ to 0.94$)$ & 0.03 \\
\hline 72 & 16.5 (15.2 to 17.9$)$ & 15.1 (13.7 to 16.4$)$ & $1.5(-0.4$ to 3.4$)$ & 4.32 (3.98 to 4.66$)$ & 3.91 (3.57 to 4.26$)$ & $0.4(-0.07$ to 0.88$)$ & 0.13 \\
\hline \multicolumn{8}{|c|}{ Hexagonality (\%) } \\
\hline 6 & $0.16(-0.48$ to 0.80$)$ & $0.15(-0.49$ to 0.80$)$ & $0(-0.88$ to 0.89$)$ & 2.19 (0.93 to 3.45$)$ & 2.31 (1.05 to 3.58$)$ & $-0.13(-1.85$ to 1.59$)$ & 0.99 \\
\hline 18 & $0.06(-0.58$ to 0.70$)$ & $0.28(-0.37$ to 0.93$)$ & $-0.22(-1.11$ to 0.67$)$ & 2.15 (0.89 to 3.42$)$ & 2.66 (1.39 to 3.93$)$ & $-0.5(-2.23$ to 1.23$)$ & 0.63 \\
\hline 36 & $0.12(-0.54$ to 0.77$)$ & 0.07 (-0.59 to 0.73$)$ & $0.05(-0.86$ to 0.96$)$ & 2.24 (0.95 to 3.53$)$ & 2.2 (0.9 to 3.49 ) & $0.04(-1.72$ to 1.81$)$ & 0.92 \\
\hline 54 & $1.20(0.52$ to 1.88$)$ & $0.37(-0.31$ to 1.06$)$ & $0.83(-0.11$ to 1.78$)$ & 4.16 (2.83 to 5.49$)$ & 2.83 (1.49 to 4.18$)$ & $1.33(-0.51$ to 3.16$)$ & 0.08 \\
\hline 72 & $0.53(-0.16$ to 1.22$)$ & $0.40(-0.31$ to 1.11$)$ & $0.13(-0.84$ to 1.10$)$ & 2.89 (1.53 to 4.25$)$ & 3.08 (1.69 to 4.47$)$ & $-0.19(-2.07$ to 1.7$)$ & 0.80 \\
\hline
\end{tabular}

Treatment effect defined as the change in the LPI group minus the change in the control group. P value for the differences between groups. Bold indicates statistical significance.

LPI, laser peripheral iridotomy. 
Table 4 Mixed model estimates of baseline factors for longitudinal crude changes of corneal endothelial cells parameters after laser peripheral iridotomy over 72 months

\begin{tabular}{|c|c|c|c|c|c|c|}
\hline \multirow[b]{2}{*}{ Predictors } & \multicolumn{2}{|c|}{ Endothelial cell density $\left(\mathrm{mm}^{2}\right)$} & \multicolumn{2}{|l|}{ Mean cell area $\left(\mu \mathrm{m}^{2}\right)$} & \multicolumn{2}{|l|}{ Hexagonality (\%) } \\
\hline & Estimate $(95 \% \mathrm{CI})$ & $P$ value & Estimate $(95 \% \mathrm{CI})$ & $P$ value & Estimate $(95 \% \mathrm{CI})$ & $P$ value \\
\hline Age at baseline (years) & $-1.91(-6.03$ to 2.21$)$ & 0.36 & $0.2(-0.54$ to 0.95$)$ & 0.59 & $-0.08(-0.17$ to 0.01$)$ & 0.09 \\
\hline Gender (male as reference) & -33.92 ( -88.31 to 20.47$)$ & 0.22 & $0.74(-9.09$ to 10.56$)$ & 0.88 & $-0.47(-1.68$ to 0.75$)$ & 0.45 \\
\hline Time (month) & $-1.91(-2.03$ to -1.78$)$ & $<0.001$ & $0.27(0.25$ to 0.29$)$ & $<0.001$ & 0.01 (0 to 0.02$)$ & 0.01 \\
\hline Axial length at baseline (mm) & $-3.6(-33.2$ to 26.01$)$ & 0.81 & $0.31(-5.01$ to 5.63$)$ & 0.91 & $0.2(-0.47$ to 0.87$)$ & 0.56 \\
\hline$A C D$ at baseline $(\mathrm{mm})$ & $4.97(-93.42$ to 103.36$)$ & 0.92 & $-1.03(-18.24$ to 16.19$)$ & 0.91 & $-0.82(-3.16$ to 1.53$)$ & 0.50 \\
\hline Lens thickness at baseline (mm) & $3.72(-57.5$ to 64.94$)$ & 0.91 & $-2.04(-12.66$ to 8.57$)$ & 0.71 & $-1.29(-2.77$ to 0.19$)$ & 0.09 \\
\hline IOP (mm Hg) & $-0.02(-0.2$ to 0.15$)$ & 0.78 & $0(-0.02$ to 0.03$)$ & 0.88 & $0(-0.02$ to 0.01$)$ & 0.57 \\
\hline Laser number of shots ( $\mathrm{n}$ ) & $-0.34(-0.86$ to 0.17$)$ & 0.19 & $0.07(-0.02$ to 0.16$)$ & 0.13 & $0(-0.01$ to 0.01$)$ & 0.80 \\
\hline Laser energy power (mJ) & $-13.02(-26.34$ to 0.3$)$ & 0.06 & $2.2(-0.05$ to 4.45$)$ & 0.06 & $0.12(-0.24$ to 0.47$)$ & 0.52 \\
\hline Total quantity of laser energy (mJ) & $0.05(-0.18$ to 0.29$)$ & 0.66 & $0(-0.04$ to 0.04$)$ & 0.90 & $0(-0.01$ to 0$)$ & 0.46 \\
\hline
\end{tabular}

Bold indicates statistical significance.

ACD, anterior chamber depth; IOP, intraocular pressure.

the month-to-month endothelial cell loss was on average 0.32 per $\mathrm{mm}^{2}$ greater for the LPI group $(\mathrm{p}<0.001)$. Risk factors for mean cell area change mirrored those for ECD change, as older patients presented larger mean cell area at each timepoint $(p=0.007)$ and the difference between groups enlarged over time $(p=0.008)$. However, no significant correlation was found between above risk factors and hexagonality of endothelial cells (with all $\mathrm{p}>0.18$ ).

Table 4 demonstrates the risk factors relating to the longitudinal changes of corneal endothelial cells parameters after receiving YAG LPI treatment. Age, gender, ocular biometrics, IOP and laser settings did not affect ECD decline and morphological change in mean cell area and hexagonality (with all $\mathrm{p}>0.05$ ). Time since LPI is the main factor associated with the longitudinal changes in endothelial cells parameters (with all $\mathrm{p}<0.01)$.

\section{DISCUSSION}

Over 72 months of observation after YAG LPI, corneal ECD declined and morphology changed in both treated and fellow eyes of PACS patients. Although the difference in ECD between treated and fellow eyes was not statistically significant before 54 months, it became statistically significant at 72 months after LPI. That said, the difference was small, $<1 \%$, and likely has no clinical impact.

The impact of YAG LPI on the corneal endothelium has been reported to be both safe and harmful in previous studies. Wishart et $a l^{16}$ reported no significant change in ECD of patients who received YAG LPI, but observed two cases of local endothelial changes. Other studies have documented a significant decline in ECD after YAG LPI without comparison to a control group. ${ }^{17} 18$ As for long-term effect, several prospective studies have not found any significant change in endothelial cell counts 1 year after YAG LPI. ${ }^{913} 19$ However, Wu et $a l^{20}$ reported a significant endothelial cell lost $(7.0 \%, \mathrm{p}<0.001)$ in 1 -year follow-up, which was much higher than that in our study $(0.97 \%$ at 18 months $)$. The significant loss of endothelial cell may be attributed to the variance of laser energy settings (total energy ranged 22.4-250.3 $\mathrm{mJ}$ ) and methods for calculating ECD (average of photographs of central and four peripheral quadrants). The current study is consistent with these previous findings of minimal impact over the short-term.

In contrast to the current findings, one retrospective study reported no significant change in the ECD in the central cornea in patients who had YAG LPI performed 1-15 years previously. ${ }^{12}$ The current study found no association between ECD loss and laser energy required to complete the LPI, suggesting the energy used to create the LPI was not the primary cause of the longterm effect and was minimally invasive to endothelial cells. It is possible that endothelial cell damage could result from environmental changes at the level of the endothelium after iridotomy owing to alterations in aqueous dynamics, breakdown of the blood-aqueous barrier and suspended debris in the aqueous humour, ${ }^{21-23}$ since these risk factors can persist after the procedure. Although the difference seen in the current study are not clinically significant and no case of corneal decompensation was observed during the follow-up, whether the difference between treated and control eyes will continue to increase beyond 72 months remains unknown.

Ageing is another important factor accounting for the ECD decline in eyes with or without YAG LPI. Previous studies have shown that normal eyes lose $0.25 \%-1 \%$ of the endothelial cells each year (table 5). The rate in untreated eyes in our study $(0.93 \%$ (95\% CI -1.26 to 0.6$)$ in 18 months) was slightly higher than that in normal eyes reported in most previous studies, although a direct comparison may not be appropriate when ethnicity and demography of the participants and methods on ECD measurement are substantially different. One possible explanation is that eyes with shallower anterior chambers are more predisposed to endothelial cell loss due to the increased possibility of irido-trabecular contact. The study by Varadaraj et $a l^{24}$ is the only study reporting that angle closure suspects have lower ECD than those with open angles, although controversially they reported established primary angle closure glaucoma had similar level of ECD as the open angle eyes. ${ }^{24}$ In another cohort of PACS subjects, the mean endothelial loss was $3.2 \%$ at 1 year and $0.9 \%$ at 3 years in PACS eyes without LPI, ${ }^{25}$ raising some concerns about the validity of data in this study. Correspondingly, the mean endothelial cell loss in our study was $0.93 \%$ at 18 months and $2.38 \%$ at 3 years. Given the fact that we did not find that corneal endothelial cell count was associated with ACD at baseline (correlation coefficient $=-0.01, p=0.55$ ), we conclude that the ECD changes over time among the untreated eyes is primarily driven by ageing effects instead of narrow angles.

The randomised controlled trial design, large sample size, high follow-up rate, long duration of observation and mixed model analysis allowing for inclusion of a time effect are the major advantages of this study. However, although the changes 
Table 5 Annual change of corneal endothelial cell density (ECD) in normal eyes

\begin{tabular}{|c|c|c|c|c|c|c|}
\hline Study & Study site & Study type & $\begin{array}{l}\text { Number of eyes/ } \\
\text { subjects }\end{array}$ & Age (years) & $\begin{array}{l}\text { Follow-up } \\
\text { (years) }\end{array}$ & ECD change/year \\
\hline Cheng et $\left.a\right|^{26}$ & UK & Longitudinal & 103 eyes & $\begin{array}{l}11 \text { participants were }<65 \text { years; } 53 \text { were } \\
\text { between } 65 \text { and } 74 \text { years and } 39 \text { were } \\
\geq 75 \text { years }\end{array}$ & 2 & $-1 \%$ \\
\hline McGill, Liakos ${ }^{27}$ & UK & Longitudinal & 48 subjects & Not mentioned & 2 & $-0.6 \%$ \\
\hline Werblin ${ }^{28}$ & USA & Longitudinal & 5 eyes & $69.3 \pm 8$ & 5 & $-0.80 \%$ \\
\hline Numa et al ${ }^{29}$ & Japan & Longitudinal & 9 subjects & $67.4 \pm 7.7$ & 5 & $\begin{array}{l}-0.26 \% \pm 1.32 \%(-8.36 \text { to } \\
\left.17.4 \text { cells } / \mathrm{mm}^{2}\right)\end{array}$ \\
\hline Bourne et $\left.a\right|^{30}$ & USA & Longitudinal & 42 subjects & $\begin{array}{l}59.5 \pm 16.8 \text { (range } 30-84 \text {, at the recent } \\
\text { follow-up) }\end{array}$ & $10.6 \pm 0.2$ & $-0.6 \% \pm 0.5 \%\left(-16\right.$ cells $\left./ \mathrm{mm}^{2}\right)$ \\
\hline Yee et $a \beta^{11}$ & USA & Cross-sectional & 60 eyes & Range 12-85 & - & -9.45 cells $/ \mathrm{mm}^{2}$ \\
\hline Rao et $a^{\beta 2}$ & India & Cross-sectional & 537 eyes & $48 \pm 16.5$ (range $20-87$ ) & - & $-0.30 \%$ \\
\hline Hashemian et $a^{33}$ & Iran & Cross-sectional & 525 eyes & $52.7 \pm 19.1$ (range 20-85) & - & $-0.60 \%$ \\
\hline Yunliang et $a l^{34}$ & China & Cross-sectional & 1329 eyes & $44 \pm 21$ (range 10-98) & - & $-0.30 \%$ \\
\hline Niederer et $a^{35}$ & Auckland & Cross-sectional & 85 subjects & $38 \pm 16$ (range 18-87) & - & $-0.50 \%$ \\
\hline Higa et $a l^{36}$ & Japan & Cross-sectional & 2602 eyes & $59.1 \pm 14.9$ & - & $-0.25 \%\left(-7.43\right.$ cells $\left./ \mathrm{mm}^{2}\right)$ \\
\hline Islam et al $\beta^{77}$ & Pakistan & Cross-sectional & 464 eyes & $39.52 \pm 18.09$ (range $12-80)$ & - & $-0.28 \%$ \\
\hline Abdellah et $a l^{38}$ & Egypt & Cross-sectional & 568 eyes & $49 \pm 15.2$ (range $20-85$ ) & - & $-0.30 \%$ \\
\hline
\end{tabular}

in the central area might be representative for the overall health of endothelium, we did not perform measurements for peripheral areas and the examination might not be in the exact same area of the cornea at every visit. Therefore, focal damage and differences in the peripheral cornea may have been missed. Further investigation of the peripheral cornea would help to understand better the long-term safety of YAG LPI. Moreover, we did not measure corneal thickness during follow-up examinations. Given the close relationship between corneal thickness and endothelial function, it is supposed that corneal thickness may not show clinically significant difference after LPI in PACS. However, more data are still needed to validate this hypothesis.

\section{CONCLUSIONS}

In summary, a significant decline in ECD was observed in both YAG LPI-treated eyes and control eyes, which was primarily attributed to the ageing effect. The difference between them was not statistically significant until 72 months after the procedure, with a smaller difference of $0.74 \%$ (95\% CI $-1.23 \%$ to $-0.24 \%)$ and minimum clinical significance.

Contributors $\mathrm{CL}$ and JZ: data analysis and interpretation, manuscript preparation. YJ and SH: data acquisition and research execution. TA: research design. PJF, DF and $\mathrm{MH}$ : research design and manuscript revision. PJF, DF and $\mathrm{MH}$ authors take joint credit and responsibility.

Funding This work is supported by the Fight for Sight (grant no. 1655) (UK), the Sun Yat-sen University 5010 Project Fund (grant no. 2007033) (China), the National Natural Science Foundation of China (grant no. 81420108008) (China), Special Trustees of Moorfields Eye Hospital (via Fight for Sight), Johns Hopkins University and Fundamental Research Funds of the State Key Laboratory in Ophthalmology (China). Professor MH receives support from the University of Melbourne Research at Melbourne Accelerator Program Professorship. The Centre for Eye Research Australia receives operational infrastructural support from the Victorian government. Dr YJ and Professor PJF supported by a grant from the British Council for Prevention of Blindness (UK). Professor PJF received additional support from the National Institute for Health Research (NIHR) Biomedical Research Centre at Moorfields Eye Hospital, London, UK (NIHR-BRC2 009; Moorfields/UCL-I00), Special Trustees of Moorfields Eye Hospital (since renamed Moorfields Eye Charity) and the Richard Desmond Charitable Foundation (via Fight for Sight UK).

Disclaimer These funding sources did not play any role in the design and conduct of the study; in the collection, management, analysis or interpretation of the data; or in the preparation, review, approval of the manuscript or decision to submit the manuscript for publication.

Competing interests None declared.

\section{Patient consent for publication Not required.}

Ethics approval This trial was approved by the Ethical Review Board of Sun Yat-sen University, the Ethical Committee of Zhongshan Ophthalmic Center and the Moorfields Eye Hospital (via the London School of Hygiene \& Tropical Medicine) and Johns Hopkins University institutional review boards. The study was conducted in accordance with the tenets of the Declaration of Helsinki.

Provenance and peer review Not commissioned; externally peer reviewed.

Data availability statement Data are available on reasonable request. Deidentified participant data that underlie the results reported in this article and statistical analysis code are available immediately following publication with no end date. Researches who provide a methodologically sound proposal can send proposal directed to mingguang_he@yahoo.com. To gain access, data requestors need to sign a data access agreement.

\section{ORCID iD}

Mingguang He http://orcid.org/0000-0002-6912-2810

\section{REFERENCES}

1 Quigley HA, Broman AT. The number of people with glaucoma worldwide in 2010 and 2020. Br J Ophthalmol 2006;90:262-7.

2 Prum BE, Herndon LW, Moroi SE, et al. Primary Angle Closure Preferred Practice Pattern(®) Guidelines. Ophthalmology 2016;123:P1-40.

3 Nolan WP, Foster PJ, Devereux JG, et al. YAG laser iridotomy treatment for primary angle closure in East Asian eyes. Br J Ophthalmol 2000;84:1255-9.

4 He $M$, Jiang $Y$, Huang $S$, et al. Laser peripheral iridotomy for the prevention of angle closure: a single-centre, randomised controlled trial. Lancet 2019;393:1609-18.

5 Shimazaki J, Uchino Y, Tsubota K. Late irreversible corneal oedema after laser iridotomy. Br J Ophthalmol 2009;93:125-6.

6 Lim LS, Ho C-L, Ang LPK, et al. Inferior corneal decompensation following laser peripheral iridotomy in the superior iris. Am J Ophthalmol 2006;142:166-8.

7 Wang PX, Koh VTC, Loon SC. Laser iridotomy and the corneal endothelium: a systemic review. Acta Ophthalmol 2014;92:604-16.

8 Faramarzi A, Yazdani S, Pakravan M. Central anterior chamber depth changes after prophylactic laser iridotomy. Optom Vis Sci 2013;90:707-10.

9 Sun X, Liang YB, Wang NL, et al. Laser peripheral iridotomy with and without iridoplasty for primary angle-closure glaucoma: 1-year results of a randomized pilot study. Am J Ophthalmol 2010;150:68-73.

10 Ramani KK, Mani B, George RJ, et al. Follow-up of primary angle closure suspects after laser peripheral iridotomy using ultrasound biomicroscopy and a-scan biometry for a period of 2 years. J Glaucoma 2009;18:521-7.

11 Ang LPK, Higashihara $\mathrm{H}$, Sotozono C, et al. Argon laser iridotomy-induced bullous keratopathy a growing problem in Japan. Br J Ophthalmol 2007;91:1613-5-5.

12 Sihota R, Agarwal E, James M, et al. Long-term evaluation of specular microscopic changes following $\mathrm{Nd}$ : YAG iridotomy in chronic primary angle-closure glaucoma eyes. J Glaucoma 2017:26:762-766-6.

13 Jamali $H$, Jahanian S, Gharebaghi R. Effects of laser peripheral iridotomy on corneal endothelial cell density and cell morphology in primary angle closure suspect subjects. J Ophthalmic Vis Res 2016;11:258-62. 
14 Jiang Y, Friedman DS, He M, et al. Design and methodology of a randomized controlled trial of laser iridotomy for the prevention of angle closure in southern China: the Zhongshan angle closure prevention trial. Ophthalmic Epidemiol 2010;17:321-32.

15 van Schaick W, van Dooren BTH, Mulder PGH, et al. Validity of endothelial cell analysis methods and recommendations for calibration in Topcon SP-2000P specular microscopy. Cornea 2005;24:538-44.

16 Wishart PK, Sherrard ES, Nagasubramanian S, et al. Corneal endothelial changes following short pulsed laser iridotomy and surgical iridectomy. Trans Ophthalmol Soc U K 1986;105(Pt 5):541-8.

17 Panek WC, Lee DA, Christensen RE. The effects of Nd:YAG laser iridotomy on the corneal endothelium. Am J Ophthalmol 1991;111:505-7.

18 Marraffa M, Marchini G, Pagliarusco A, et al. Ultrasound biomicroscopy and corneal endothelium in Nd:YAG-laser iridotomy. Ophthalmic Surg Lasers 1995;26:519-23.

19 Schwenn 0, Sell F, Pfeiffer N, et al. Prophylactic Nd:YAG-laser iridotomy versus surgical iridectomy: a randomized, prospective study. Ger J Ophthalmol 1995;4:374-9.

20 Wu SC, Jeng S, Huang SC, et al. Corneal endothelial damage after neodymium:YAG laser iridotomy. Ophthalmic Surg Lasers 2000;31:411-6.

21 Higashihara H, Sotozono C, Yokoi N, et al. The blood-aqueous barrier breakdown in eyes with endothelial decompensation after argon laser iridotomy. Br J Ophthalmol 2011;95:1032-4.

22 Yamamoto Y, Uno T, Joko T, et al. Effect of anterior chamber depth on shear stress exerted on corneal endothelial cells by altered aqueous flow after laser iridotomy. Invest Ophthalmol Vis Sci 2010;51:1956-64.

23 Kerr Muir MG, Sherrard ES. Damage to the corneal endothelium during Nd/YAG photodisruption. Br J Ophthalmol 1985;69:77-85.

24 Varadaraj V, Sengupta S, Palaniswamy K, et al. Evaluation of angle closure as a risk factor for reduced corneal endothelial cell density. J Glaucoma 2017;26:566-70.

25 Kumar RS, Baskaran M, Friedman DS, et al. Effect of prophylactic laser iridotomy on corneal endothelial cell density over 3 years in primary angle closure suspects. $\mathrm{Br}$ J Ophthalmol 2013;97:258-61.
26 Cheng H, Jacobs PM, McPherson K, et al. Precision of cell density estimates and endothelial cell loss with age. Arch Ophthalmol 1985;103:1478-81.

27 McGill J, Liakos G. Complications of anterior chamber intraocular lenses and their effect on the endothelium. Trans Ophthalmo/ Soc U K 1985;104(Pt 3):273-7.

28 Werblin TP. Long-term endothelial cell loss following phacoemulsification: model for evaluating endothelial damage after intraocular surgery. Refract Cornea/ Surg 1993;9:29-35.

29 Numa A, Nakamura J, Takashima M, et al. Long-term corneal endothelial changes after intraocular lens implantation. Anterior vs posterior chamber lenses. Jpn J Ophthalmol 1993;37:78-87.

30 Bourne WM, Nelson LR, Hodge DO. Central corneal endothelial cell changes over a ten-year period. Invest Ophthalmol Vis Sci 1997;38:779-82.

31 Yee RW, Matsuda M, Schultz RO, et al. Changes in the normal corneal endothelial cellular pattern as a function of age. Curr Eye Res 1985;4:671-8.

32 Rao SK, Ranjan Sen P, Fogla R, et al. Corneal endothelial cell density and morphology in normal Indian eyes. Cornea 2000;19:820-3.

33 Hashemian MN, Moghimi S, Fard MA, et al. Corneal endothelial cell density and morphology in normal Iranian eyes. BMC Ophthalmol 2006;6:9.

34 Yunliang S, Yuqiang $\mathrm{H}$, Ying-Peng L, et al. Corneal endothelial cell density and morphology in healthy Chinese eyes. Cornea 2007;26:130-2.

35 Niederer RL, Perumal D, Sherwin T, et al. Age-related differences in the normal human cornea: a laser scanning in vivo confocal microscopy study. Br J Ophthalmol 2007:91:1165-9

36 Higa A, Sakai H, Sawaguchi S, et al. Corneal endothelial cell density and associated factors in a population-based study in Japan: the Kumejima study. Am J Ophthalmol 2010;149:794-9.

37 Islam QU, Saeed MK, Mehboob MA. Age related changes in corneal morphological characteristics of healthy Pakistani eyes. Saudi J Ophthalmol 2017;31:86-90.

38 Abdellah MM, Ammar HG, Anbar M, et al. Corneal endothelial cell density and morphology in healthy Egyptian eyes. J Ophthalmol 2019;2019:1-8. 